should be required. A larger proportion of women in the age-group 20-30 should be made available for shipbuilding, and once again the importance of welfare work is stressed and the appointment of women welfare supervisors urged.

Personnel management and questions of morale and co-operation recur in this report, as well as of management, and the Committee emphasizes the wisdom of taking all possible steps to put before the workers the full gravity of the shipping position.

It is, however, the section on technique, design and research that is of the greatest interest to scientific workers. Here a careful examination of pre-fabrica. tion of hull portions from the point of view of economy of labour is recommended. Under present conditions, the use of welding beyond a certain point does not appear to effect any saving of time as compared with riveting by skilled squads. Expert opinion inclines to the view that in British yards a combination of the two methods will give the best output. There appears still to be some room for standardization of sectrons and fittings and the elimination of nonessentials, and the Committee suggests that the British Classification Societies should review their rules to ascertain how far production could be assisted without lowering standards of safety.

It is disappointing to find in this section of the report the opinion that the resources of the William Froude Laboratory have not been fully exploited for war purposes by shipbuilders or by the Admiralty. The Committee therefore recommends that shipbuilders should be instructed to consult the National Physical Laboratory at the appropriate stages in the design of all proposed new types of hull, and that the Admiralty should see that full technical liaison is maintained with the Laboratory. Similarly, commenting on the delays and interruptions in the dissemination of the results of research into the problems of merchant shipbuilding and marine engineering, and the actual decrease in such research by the Institute of Welding, the Iron and Steel Institute, or under the auspices of the three universities possessing chairs of naval architecture, since the War, the report recommends that the Admiralty should establish an organization with the specific responsibility for directing and co-ordinating all development and research in respect of merchant shipbuilding. Coupled with this there is recommended, first, the appointment, in close association with this organization, of a technical intelligence staff, and, secondly, that where several firms are building similar vessels, one of them should act as leader for each part of the complete vessel and machinery, and be responsible for development and improvement in production technique for that part.

Apart from these recommendations to rectify a disturbing lapse of research activities on the part of institutions which might properly have been expected to intensify them, there are other recommendations affecting organization, such as a survey of all yards engaged exclusively on naval work to ascertain whether a small admixture of merchant shipbuilding could assist the maximum output without impeding naval work, a review of the allocation of merchant programmes with the object of reducing the number of types of merchant ships built in the same yard, and a survey of all yards not now in use for shipbuilding, and the selection for re-opening of those which could most rapidly be brought into use. On the other hand, shipbuilding has not been delayed from lack of materials, and the main conclusion of the report appears to be that attention to the human side of personnel problems and to the organization of facilities and supplies of labour and materials in key with the demands of the country as a whole are the chief essentials to ensure the execution of a programme adequate to meet the country's needs.

\section{TUBERCULOSIS IN WAR-TIME}

$T$ UBERCULOSIS in war-time has recently been discussed by Sir Arthur MacNalty in a Chadwick Public Lecture (see p. 676 of this issue). It is also the subject of an excellent report reviewing critically the available evidence and making recommendations, which has been prepared by a committee of the Medical Research Council (London : H.M. Stationery Office, 1942. 9d. net).

The Committee finds that there has been a significant increase in the incidence and mortality of tuberculosis affecting all age groups since the War began. Modern war creates social and industrial upheavals responsible for many factors which tend either to increase the risk of contact with tuberculous persons or to a lowering of resistance to the tubercle bacillus.

The Committee makes many recommendations for preventing further deterioration in the trend of tuberculosis mortality :

(i) To reduce the spread of bovine infection from milk, the widest possible extension of pasteurization should be undertaken.

(ii) To detect pulmonary lesions at an early stage, mass radiographic surveys should be made (vide infra).

(iii) Improvements in the care and after-care of infected persons are necessary, with special reference to increasing the number of available beds in sanatoria and to financial aid to the patients and their dependants.

(iv) In order to raise resistance to the tubercle bacillus, especially in susceptible groups of the population, close attention should be paid to the working conditions of young employees.

(v) Additional measures are suggested; namely, the examination of contacts, investigation of tuberculosis in mental hospitals, propaganda to the medical profession and the public, and a re-organization of the tuberculosis services.

\section{Mass Radiography}

The Committee pays especial attention to the value of mass radiographic surveys of selected groups of the community to discover the disease at an earlier stage than in most cases when the diagnosis is first made. The technique of miniature radiography, especially by virtue of its speed and economy, has made mass surveying a feasible measure. It should be stated that a subject showing positive findings in the miniature radiograph is only regarded as a suspect until full clinical, bacteriological and radiological (full-size film) evidence proves or disproves the presence of significant disease.

Miniature radiography implies the photography of the fluorescent screen image produced by $\mathrm{X}$-rays and is practised in two forms : $(a) 5$ in. $\times 4$ in. miniature (as used widely in the United States); (b) $35 \mathrm{~mm}$. cine film miniature recording. Many units using the cine film will shortly be available in Great Britain : a technical sub-committee (the report of which 
appears as an appendix) has laid down the requirements for this apparatus.

Mass radiography may be used :

(i) Pre-employment : examination of groups about to enter employment (e.g., the Services, industry).

(ii) During employment: examination of groups of persons, for example, in munition factories, without selection as to age or sex.

(iii) Periodically : examination of groups at regular intervals : this is regarded as the ideal method for the early diagnosis, and thus for the control, of pulmonary tuberculosis. In the difficult conditions of war-time, periodic mass radiography would probably have to be confined to specially selected groups, for example, munition workers, medical students and nurses, and merchant seamen.

In the main report, the Committee states that "mass miniature radiography requires a considerable degree of organization and planning ahead", but it is left to the Sub-Committee to emphasize that the method "should not be lightly undertaken. A very high standard of quality of miniature radiography is necessary for correct interpretation and the latter requires the highest radiological skill". It is of the greatest importance that every effort should be made to secure and preserve the highest technical standard : it is on this that the success of the method depends. The proposed vast surveys should be watched by a carefully chosen central advisory (or controlling) board of experts acting for the Ministry of Health.

\section{TRAVELLING WAVES IN HIGH- VOLTAGE ALTERNATOR WINDINGS}

A PAPER by E. Friedländer (J. Inst. Elec. Eng. A 89, Pt. 2, No. 11; October 1942) discusses the theory of this subject, pointing out that the security of the windings of an alternator generating at $22 \mathrm{kv}$. or above and connected directly to a network depends mainly on the ability of the insulation to withstand surge voltages. The distribution of surge voltages in the various types of stator winding hitherto adopted in commercial practice is examined, together with the relation of this distribution to that of the effective insulation available. As alternators nearly always operate with the neutral point of the windings unearthed, the voltage stresses on the insulation near the neutral in these circumstances are determined, and the danger of the use of graded insulation is discussed. In no case does there appear to be an inherent tendency for all transient voltages to be distributed over the length of the stator winding in the same proportion as the generated voltage of the machine.

The problem of the design of an alternator to generate directly at $22 \mathrm{kv}$. or $33 \mathrm{kv}$., or at higher voltages, appears to be best solved by avoiding graded insulation and applying the conventional methods of construction hitherto used for $6 \cdot 6 \mathrm{kv}$. or $11 \mathrm{kv}$., the insulation being increased in thickness to carry the increased voltage. Such conventional windings have great inherent security against transient surge voltages, which affect chiefly the interturn insulation, and their major insulation can be easily and cheaply protected against more sustained overvoltages by means of surge arresters, preferably applied both to the terminals and to the neutral if this is unearthed.
These conclusions have arisen from theoretical considerations based on a number of approximations which, however, it has not been possible to check by experiment. Any experimental work, however, may be subject to considerable errors due to the depth of penetration of the flux into the iron of the core varying with the current of the conductors. The actual wave shapes found experimentally with low currents thus might not agree with the theoretical results, which are based on conditions that probably are better approached with heavy surge currents. The results obtained lend no support to the view that the distribution of the capacitances in the concentric-winding conductor would give even distribution of surge stresses over its different sections.

\section{DISPLACEMENT METHOD OF WEIGHING LIVING ORGANISMS}

A.G.LOWNDES has described* not only the method $\mathrm{A}$ indicated by the title of his paper but also methods for determining the water content of living (especially aquatic) organisms and in some cases the density of their protoplasm. The accurate determination of the weight is (with marine animals) achieved by weighing a density bottle full of sea water and estimating the halide in the contents of the bottle gravimetrically, followed by a weighing of the bottle containing sea water and a living marine organism and an estimation of the halide content of the water in the bottle. All these data may be obtained with great accuracy and from them the author calculates the weight, volume and density of the organism.

The ratio of density of organism to density of medium (multiplied by 1,000 by the author and called the "sinking factor" or S.F.) is a measure of the effort that must be exerted by the organism to keep afloat. For the conger, the S.F. is 1,000, and so there is no tendency to sink, whereas the lobster with a higher S.F. will sink unless work is done to keep afloat, although the necessary expenditure of energy is reduced if the female lobster is carrying a load of eggs or embryos, because its S.F. is then lowered although its weight is, of course, increased.

The water content of aquatic organisms is deter. mined by a modification of Dean and Stark's method, and here a novel technique is employed that obviates the introduction of errors due to the presence of extraneous water that wiping fails to remove. The author determines the water content of the animal and a known amount of sea water together, and from a knowledge of the composition of the latter the amount of water in the organism is readily obtained by difference. In sponges that have been dried during a water determination, the silica is estimated and, making allowance for the presence of silica, the density of the living protoplasm is computed with a considerable degree of accuracy; minor modifications of the methods are necessary when freshwater organisms are being used. The interest of the methods lies in the high degree of accuracy attained, which makes possible investigation of the precise physiological and physical relations existing between aquatic organisms and their environment, and so paves the way for the advancement of knowledge in this field.

*J. Marine Biol. Soc., 25 (Oct. 1942). 